\title{
Transportation infrastructure impacts on firm location: the effect of a new metro line in the suburbs of Madrid
}

\author{
Lucia Mejia-Dorantes , Antonio Paez , Jose Manuel Vassallo
}

\begin{abstract}
Firm location patterns emerge as a consequence of multiple factors, including firm considerations, labor force availability, market opportunities, and transportation costs. Many of these factors are influenced by changes in accessibility wrought by new transportation infrastructure. In this paper we use spatial statistical techniques and a micro-level data base to evaluate the effects of Madrid's metro line 12 (known as Metrosur) expansion on business location patterns. The case study is the municipality of Alcorcon, which is served by the new metro line since 2003. Specifically, we explore the location patterns by different industry sectors, to evaluate if the new metro line has encouraged the emergence of a "Metrosur spatial economy". Our results indicate that the pattern of economic activity location is related to urban accessibility and that agglomeration, through economies of scale, also plays an important role. The results presented in this paper provide evidence useful to inform efficient transportation, urban, and regional economic planning.
\end{abstract}

\section{Introduction}

Commercial establishment location patterns are a consequence of multiple factors. Firms select a site for an establishment based whether the firm is market- or resource-oriented, the level of access to markets it can achieve, the availability of labor and resources, and the presence of appropriate real estate. Once a firm is established in a specific location, it also may generate interactions with other firms. It may attract complementary activities, developing local markets, or it may repel other business activities that try to avoid competition. Firms can find proximity to other business advantageous or disadvantageous depending on the character of interactions. In most cases, there are reasons to believe that firms are not indifferent to the presence or absence of other firms in their neighborhood.

The theoretical foundation for the location patterns of firms is given by the concept of market areas. A market area is the geographical extent of a firm's consumer base, and is determined by the firm's spatial pricing, the distribution of population, and the elasticity of demand of the good or service offered. In order to maximize revenue and profit, firms consider how locating at a specific location would affect their market potential based on their ability to set a price consistent with their marginal revenue and marginal costs. Consumers, it is assumed, will compare for competing establishments their delivered price, which depends on the cost of transportation. Other things being equal, the cost of transportation generates in consumers a tendency to prefer firms with the lowest delivered price. Firm locational patterns emerge as a consequence (Hoover and Giarratani, 1971).

Several location patterns may occur when a population of firms is examined. The case of firm repulsion may take place when enterprises are market-oriented and the market is dispersed, or alternatively when firms are resource-oriented and the sources of input are dispersed. Hence, firms may be competing for the same market or raw materials. Firm clusters, on the other hand, may result from demand or production characteristics of the activity in question. Foremost, agglomerative forces arise from the external economies of a cluster which is linked to input suppliers (Cohen and Paul, 2005). Sometimes spatial competition may lead to mutual attraction of sellers as well. Moreover, as urban areas grow, they become increasingly capable of supporting activities and services that are external to any cluster but which generate economies for a number of clusters. Finally, repulsion and attraction may operate jointly when sellers have market areas and buyers at the same time have established supply areas. Therefore the firm benefits from demand of the product at a well-known specific location (Hoover and Giarratani, 1971). The net effect of this joint process is an empirical 


\begin{tabular}{|l|c|c|}
\hline \multicolumn{2}{|c|}{ Madrid transportation modal share, 2004 } \\
\hline \multicolumn{1}{|c|}{ Mode } & Urban & Metropolitan \\
\hline Walking & $32.00 \%$ & $30.20 \%$ \\
\hline Urban Bus & $15.50 \%$ & $0.10 \%$ \\
\hline Metro & $19.90 \%$ & $3.70 \%$ \\
\hline Suburban Bus & $0.40 \%$ & $12.10 \%$ \\
\hline Suburban Train & $2.30 \%$ & $8.50 \%$ \\
\hline Car & $22.40 \%$ & $44.50 \%$ \\
\hline Taxi & $6.60 \%$ & $0.40 \%$ \\
\hline Motorbike & $0.70 \%$ & $0.50 \%$ \\
\hline
\end{tabular}

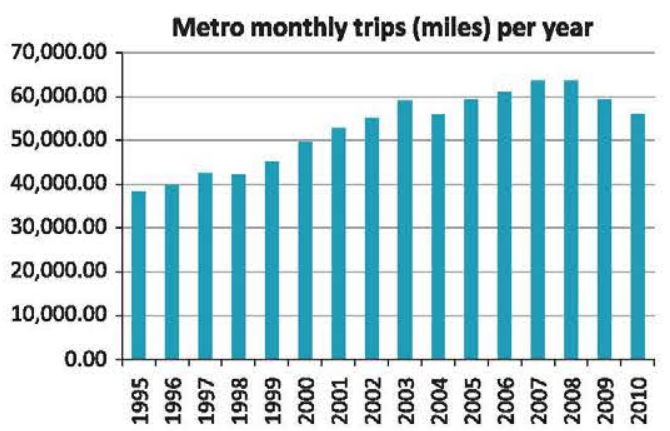

Fig. 1. Modal share of urban and metropolitan trips in 2004 (Jordá, 2009) and metro's monthly trips per year (Spain National Statistics Bureau, 2010).

question that must be examined in the context of the various factors that influence location.

In practice, empirical analysis of spatial and temporal patterns of firm location is complicated due to lack of detailed firmographic data. Very few studies are available that examine these issues (Baumont et al., 2004; Manzato et al., 2011; Maoh and Kanaroglou, 2007). The studies of Maoh and colleagues (Maoh and Kanaroglou, 2007; Maoh, 2007; Maoh and Kanaroglou, 2009; Maoh et al., 2010; Ryan et al., 2009) for example, were facilitated by access to firm micro-data through a special program with Statistics Canada that allowed the researchers to work at a secure data facility site in Ottawa. This program has since been discontinued, and other suitable databases are typically not easy to access or simply do not exist.

The aim of this paper is to investigate the impact of changes in the accessibility surface on the location pattern of firms. Specifically, we hypothesize that the change in accessibility wrought by new infrastructure, with the consequent localized, and spatially differentiated reduction in transportation costs, affects the locational patterns of businesses establishments, and generates a tendency to locate near transit facilities. Furthermore, we hypothesize that the location of firms is also affected by the surrounding opportunity landscape, and the presence of other firms that may generate economies of agglomeration and/or competition.

The case study presented in this paper is the Madrid Region. The focus is on the municipality of Alcorcon in the southwest of Madrid City, a zone long underserved by urban mass transportation. In order to improve service, a new metro line (Line 12), known as "Metrosur", was built between 1999 and 2003 to connect the five most important municipalities in the region with each other, and also with Madrid City (see Fig. 2). The new infrastructure, which started operations in 2003 , is a circular line that provides connectivity with commuter rail and the main segments of the metro network.

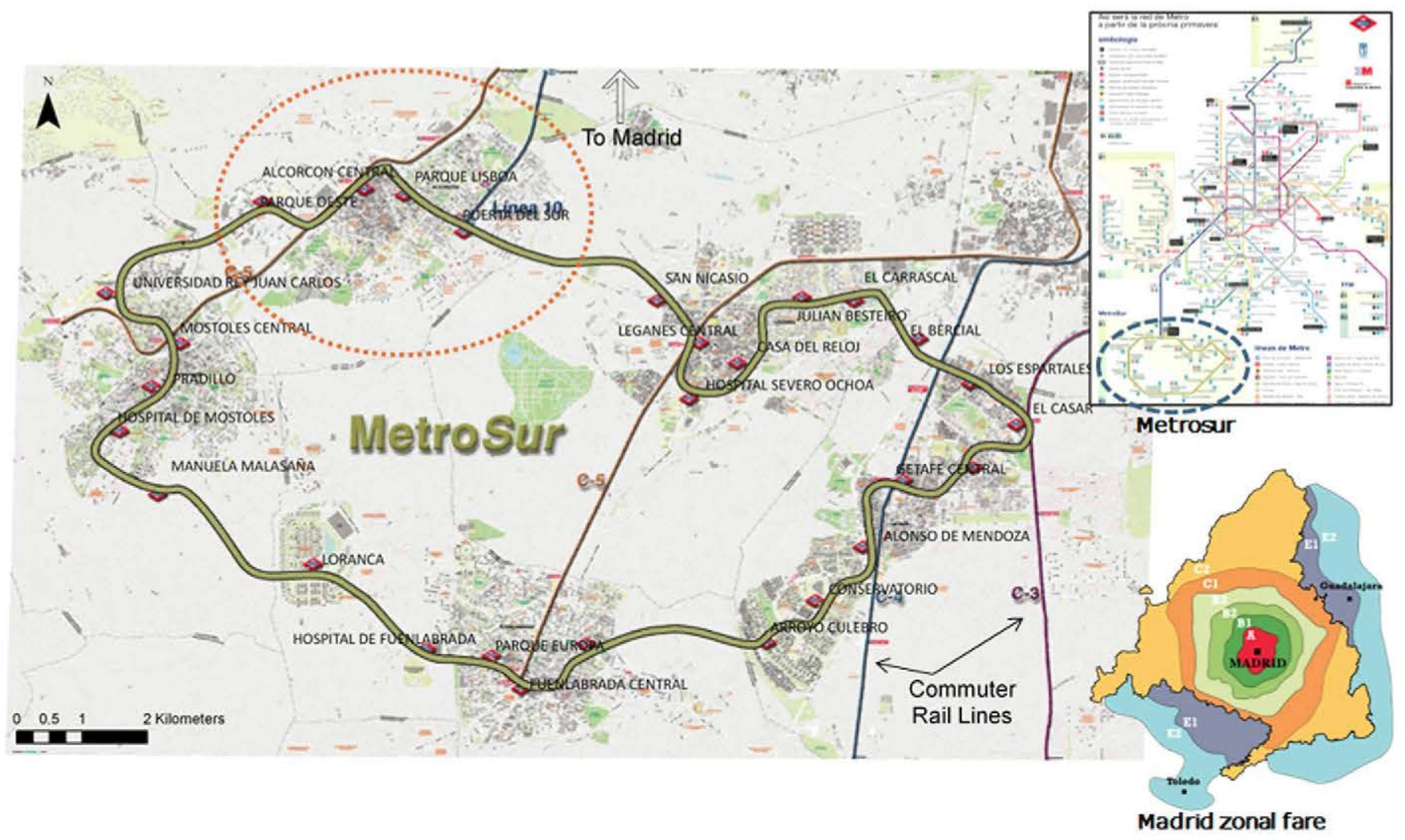

Fig. 2. Map of Metrosur, Madrid metro network and transportation zonal fares. 
One of the main stated objectives of this metro line was to promote economic activity within the region, under the expectation that an improved transportation network in the area would facilitate not only travel to Madrid but would also become a pole of attraction for different firms that would help to create jobs in the region.

Herein, we propose to evaluate the impact of the new metro line the location pattern of business establishments. This research makes use of micro-data from the years 1998 and 2007 collected by the Bureau of Statistics of the Madrid Region. Analysis is based on the application of a spatial multinomial logistic model, which allows us to assess the impact of geographical attributes on the occupation of existing sites. This includes proximity to stations of the newly developed metro line, as well as proximity to other establishments.

The paper is organized in the following way. In the second section we discuss the background to this research. In the third section, we discuss the characteristics of the study area. In the fourth section, we describe the methods and models used. In the fifth section, we present and discuss the results. The last section offers a final discussion and the main conclusions.

\section{Background}

During the past few decades, urban areas around the globe have experienced important changes due to decentralization of activities. Urban form has in many places evolved, and is increasingly less defined by a unique pole of economic activity, i.e., a traditional Central Business District (CBD), and more by multiple suburbanized economic poles. Employment, housing and population are therefore reorganized in new areas (Cuthbert and Anderson, 2002). Transportation, it is commonly agreed, has played a key role in facilitating and even encouraging this type of development.

Several factors are important for the development of locational patterns: available labor force and its cost, market opportunities, taxes and subsidies (if available), infrastructure, transportation accessibility, space, amenities and even personal decisions (Banister and Berechman, 2001; Beckmann, 1999; Small, 1982). Competition among business firms is also an important factor (Hoover and Giarratani, 1971). Furthermore, the location of firms and industries is influenced by geographic factors and agglomeration (Yrigoyen and Garcia, 2009). The latter is a consequence of economies of scale, and means that the profit of some firms is improved when they operate in the context of a larger local economy, taking advantage of being closer to related firms (Cohen and Paul, 2005; Johansson and Quigley, 2003). When interdependent industries are attracted due to their economic linkages, it is even possible that these linkages attract them to other locations, such as out of urban centers. Whenever different types of firms locate closer, they eventually create clusters, which impact the way commercial and industrial land uses are defined over space. Eventually, such a process of co-location can have broader implications for urban form (Maoh and Kanaroglou, 2007). If different industrial sectors take advantage of physical proximity to related firms, these agglomerations become economic poles. In order to create agglomeration economies, a powerful labor force should be present (Feser and Sweeney, 2000; Maoh, 2005).

Public transportation infrastructure can be a powerful driver of urban form. Authors, such as Banister and Berechman (2000), classify those effects as: transportation-related effects, land-use effects, and effects on jobs and business activities. The general explanation for these effects is that transit facilities increase the accessibility to public transportation for the people living nearby, therefore reducing their travel time to other destinations in urban areas. Similarly, business activities (both offices and shops) near the stations also enjoy some advantages: jobs and shops are now more accessible for those coming from any destination; business activities close to the stations enjoy either the increase in the number of people who pass by near the shops in their way to or from the stations, or the increase in the qualified labor force they can draw upon.

The effects on jobs and businesses are usually noticed over the long term and are mostly those produced by agglomeration economies (Boarnet, 2006; Fujita, 1989). Moreover, researchers such as Mas and Maudos (2004), have shown that transportation infrastructure does not only have significant effects on the area directly influenced by it, but also on areas close or connected to it. In fact, economic development and economic growth are the result of the long-term increase in economic activities which can be attributed in part to the direct impact of improvements in the transportation infrastructure, such as travel time reductions that promote industrial agglomeration. However, as noticed by Banister and Berechman (2001), economic development requires a social and political framework that prompts such economic growth, which includes: policy actions and institutional support, the necessary funds for an efficient investment, and economic conditions as well as positive externalities.

On the other hand, authors such as Cervero and Aschauer for Cambridge Systematics (1998), and Schwanen et al. (2004) mention that Transit-Oriented Development (TOD) initiatives are important urban policy actions in order that areas around the transport stations become more attractive either for housing or for firms. These initiatives include among others: high density developments near transit stations, pedestrian-friendly neighborhood design especially through dense street patterns and mixed land uses. Different studies note as well, that the characteristics of the street network design determine the attractiveness of transit stations because most of the riders get to the stations by walking. Therefore, traditional street patterns (narrow roads with frequent crossings) enhance pedestrian access; while, newly developed areas designed for private transport (longer and wider roads, irregular patterns) limit pedestrian access to the stations (Gutiérrez and García-Palomares, 2008; Mejia-Dorantes and Vassallo, 2010).

\section{Study area and data}

\subsection{Regional context: the Madrid Region, the metro rail system and the Municipality of Alcorcon}

Almost six million people live in the Madrid Metropolitan Area (MMA) (CRTM, 2006). This area is composed of a large economic and social pole at the center (Madrid City with a population slightly over three million) and a set of small and medium-sized cities around this pole. Madrid City can be reached through both private and public means of transportation.

In terms of public transportation, the system in Madrid is multimodal: commuter rail and metro network, urban and interurban buses, along with some relatively new light rail services. Fig. 1 shows the modal share either for urban trips or for metropolitan trips and the evolution of metro's monthly trips per year. The percentage of people with a monthly travel pass living in zone A is equal to $28.8 \%$; while this percentage decreases as we move farther from the core of Madrid: the percentage of people living in zone B with a travel pass is equal to $20.7 \%$ and equal to $17.2 \%$ in the case of zone C (TARYET \& IMOP, 2005). This executive report also states that people are more prone to have a travel pass if their trips are multimodal.

The system is divided into different fare zones (known as A, B1, $B 2, B 3, C 1, C 2, E 1$ and E2), with fares increasing based on distance from the core (zone A). The monthly travel pass allows users to take any transport mode (buses, metro and commuter train) within 
its validity range. The Madrid metro network and the configuration of the different zonal fares in the region of Madrid are shown in Fig. 2.

In the last three decades, the municipality of Madrid itself has substantially restrained new real estate development inside its boundaries, leading to high real estate prices. Some municipalities outside of, but surrounding Madrid City, have reacted by promoting large real estate developments in order to increase the supply of affordable housing. As a consequence, some municipalities which four decades ago were small towns with little connection to Madrid City have within the span of a few years evolved into satellite cities with large populations, and substantial numbers of commuters who travel regularly to Madrid City. The largest growth occurred in five municipalities located to the southwest of Madrid (Alcorcon, Mostoles, Leganes, Getafe and Fuenlabrada). This situation is especially remarkable considering that the combined population of these municipalities has reached almost 1 million, compared to a population of slightly over 3 million in Madrid City.

Fig. 3 shows the location of these municipalities within the MMA. The shaded areas represent Madrid City. The darkest shaded areas show the central districts, while the areas that are only slightly shaded show the outer districts. Until recently, the metro system of Madrid City did not extend beyond the city limits so as to reach other municipalities (shaded areas).

The urban areas of the five municipalities mentioned before had largely unconnected population centers with mostly undeveloped areas between them. Local transportation systems in these cities used to focus on connecting these municipalities to the City of Madrid through both regional buses and commuter trains. However, transit services linking these five municipalities were extremely limited.

As these municipalities continued to grow, one of their most important issues became their status as dormitory communities. Accordingly, business activities and consequently local employment opportunities were noticeably scarce in these municipalities. Appraising this situation, the Regional Government of Madrid adopted as a policy the promotion of a more balanced growth of those municipalities, and as a tool, the creation of greater transportation accessibility and better linkages among these five municipalities in order to create an economic region alternative to Madrid. A new circular metro line (line 12 or Metrosur) connecting

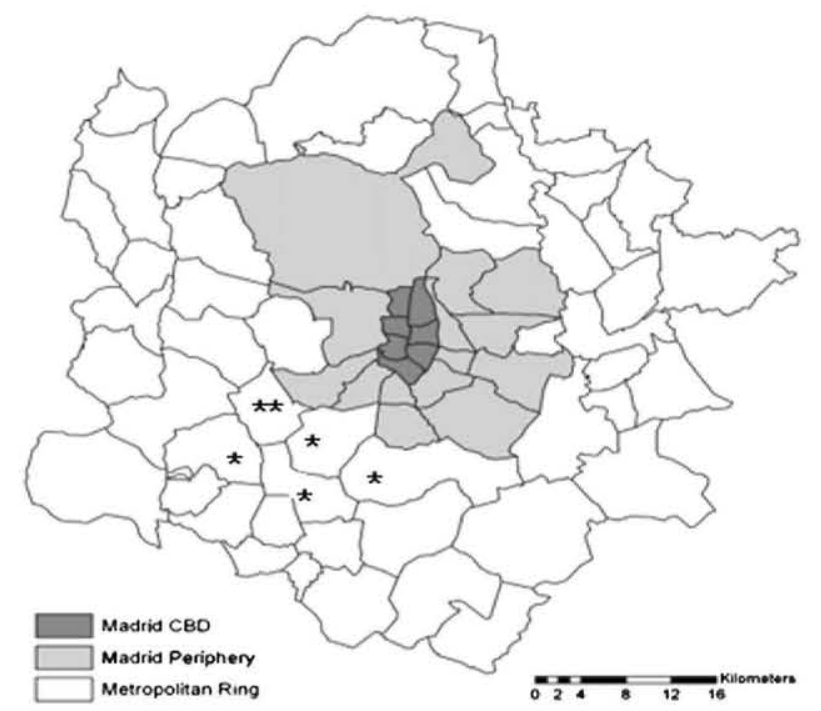

Fig. 3. Madrid metropolitan area (MMA). The municipalities marked with (*) correspond to the municipalities connected by Metrosur and Alcorcon is marked with $(* *)$. those five municipalities of the southwest of Madrid was the tangible outcome of the policy.

Metrosur was built entirely underground in order to minimize negative environmental impacts. This was the first time that the metro network was extended beyond Madrid City itself. This new line, currently in operation, contains 28 stations and is additionally connected to the metro network of the central city through Line 10. It also shares six transfer stations with the commuter rail lines "Cercanias" (see Fig. 2). The construction of Metrosur began in 1999 and its operation started in April 2003. It is a circle line of about $54.6 \mathrm{~km}$, and its construction cost was about 52.7 million $€ / \mathrm{km}$, including the trains (Melis et al., 2003).

Alcorcon is the closest municipality to Madrid City served by Metrosur. The total area of its territory is about $33.6 \mathrm{~km}^{2}$, and its population has notably increased over the years. Table 1 shows its most important characteristics.

Alcorcon is served by different transport systems (see Figs. 3 and 4):

Four metro line 12 stations. This line is the one known as Metrosur: Puerta del Sur (transfer to line 10), Parque de Lisboa, Alcorcon Central (transfer to Cercanias), and Parque Oeste.

Table 1

Alcorcon's urban, socio-economic and other characteristics (Bureau of Statistics of the Madrid Region, 2011).

\begin{tabular}{|c|c|c|c|}
\hline & Alcorcon & $\begin{array}{l}\text { Madrid } \\
\text { Region }\end{array}$ & Year \\
\hline Territory & $33.6 \mathrm{~km}^{2}$ & $8028 \mathrm{~km}^{2}$ & \\
\hline Distance to the Capital & $13 \mathrm{~km}$ & & \\
\hline Population & 167,967 & 6386,932 & 2009 \\
\hline Men & 82,705 & 3094,874 & 2009 \\
\hline Women & 85,262 & 3292,058 & 2009 \\
\hline Female rate & 1.03 & 1.06 & 2009 \\
\hline \multicolumn{4}{|l|}{ Index per 100 inhab. } \\
\hline Inhabitants under 14 years & 14.39 & 14.93 & 2009 \\
\hline Inhabitants over 65 years & 14.55 & 14.43 & 2009 \\
\hline \multicolumn{4}{|l|}{ Labor market } \\
\hline People with social security $/ 1000$ inhab. & 269.39 & 466.03 & 2008 \\
\hline Rate of female economic activity & $42.34 \%$ & $42.59 \%$ & 2001 \\
\hline Unemployment/100 inhab. & 4.74 & 4.01 & 2008 \\
\hline \multicolumn{4}{|l|}{ Macroeconomic info } \\
\hline Gross Domestic Product (Per Capita) & $16,305.00$ & $31,577.00$ & 2007 \\
\hline Income Per Capita & $14,963.83$ & $17,996.98$ & 2007 \\
\hline \multicolumn{4}{|l|}{ Socioeconomic condition/1000 inhab. } \\
\hline Managers and technicians & 138.56 & 159.88 & 2001 \\
\hline Businessmen in charge of workers & 20.3 & 22.17 & 2001 \\
\hline Non-skilled workers & 105.46 & 90.85 & 2001 \\
\hline \multicolumn{4}{|l|}{ Pop/1000 inhab. working at } \\
\hline Retail and food services & 106.15 & 107.43 & 2008 \\
\hline Transport and communications & 22.35 & 37.5 & 2008 \\
\hline Financial services & 8.21 & 17.49 & 2008 \\
\hline Professional services & 37.66 & 112.99 & 2008 \\
\hline Social services and personal services & 57.05 & 79.22 & 2008 \\
\hline $\begin{array}{l}\text { Public administration and other } \\
\text { services }\end{array}$ & 21.23 & 49.52 & 2008 \\
\hline \multicolumn{4}{|l|}{ Housing } \\
\hline Family-owned & $89.54 \%$ & $82.02 \%$ & 2001 \\
\hline In rent & $7.98 \%$ & $13.62 \%$ & 2001 \\
\hline Other & $2.48 \%$ & $4.36 \%$ & 2001 \\
\hline Persons/house & 3.01 & 2.88 & 2001 \\
\hline \multicolumn{4}{|l|}{ Education } \\
\hline Illiterate & $1.50 \%$ & $1.77 \%$ & 2001 \\
\hline No education & $10.70 \%$ & $9.97 \%$ & 2001 \\
\hline Primary education & $19.00 \%$ & $17.44 \%$ & 2001 \\
\hline High-school education & $54.18 \%$ & $50.09 \%$ & 2001 \\
\hline University studies (college and higher) & $15.15 \%$ & $20.74 \%$ & 2001 \\
\hline \multicolumn{4}{|l|}{ Others } \\
\hline Cars/1000 inhab. & 472.53 & 533.38 & 2008 \\
\hline
\end{tabular}




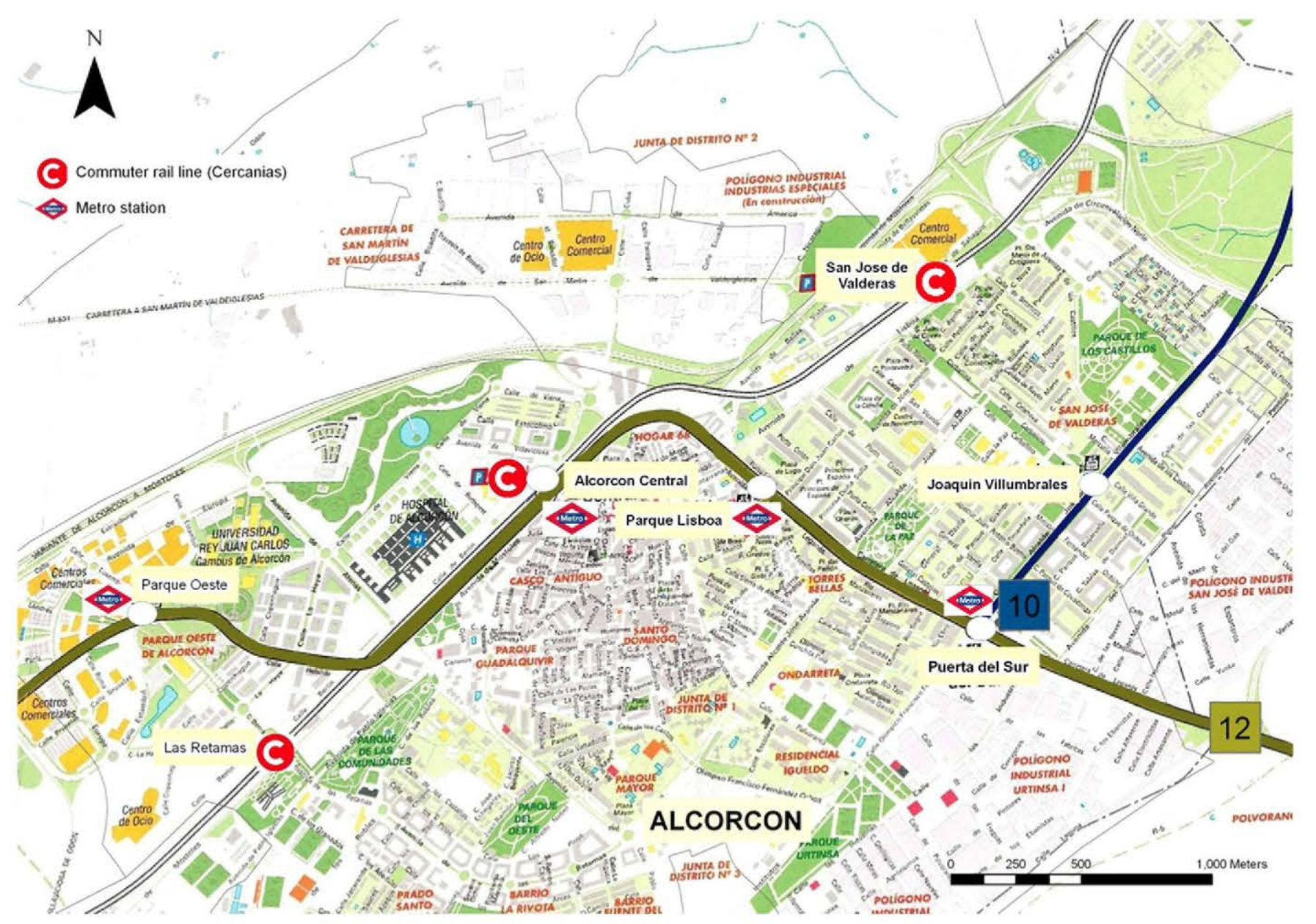

Fig. 4. Metrosur and Cercanias stations within Alcorcon (self-modified after a map from Melis et al. (2003)).

Two metro line 10 stations: Puerta del Sur (transfer to Metrosur) and Joaquin Villumbrales. This line takes people directly to Madrid downtown. Moreover the extension of this metro line to Alcorcon was built at the same time as Metrosur was built. Three commuter train stations. This system is also known as Cercanias: Las Retamas, Alcorcon Central (transfer to Metrosur) and San Jose de Valderas.

It is served as well by different interurban buses that have stops through all the territory.

Recently, a light rail line started to operate through the west of Alcorcon and has two stations; however it has limited connection to the urban areas.

Furthermore, Alcorcon is the multimodal gateway to the rest of the municipalities.

\subsection{Data}

The dataset used in this research includes detailed geographical information regarding the location of economic activities within Alcorcon from 1998 to 2007, as provided by the Bureau of Statistics of the Madrid Region. In general terms, data for the region are limited (Le Gallo and Chasco, 2008). For each year, the Bureau gives the exact location of the establishment, so-called portal, that is, an address available for commercial activity. The availability of a geographical reference makes it possible to relate each portal to spatial variables of interest. In addition, the database contains the type of economic activity to the Spanish CNAE codes (National
Classification of Economic Activities), as seen in Table 2. However, other data to characterize the establishments do not exist, such as number of employees, revenue, and profit.

The set of spatial variables considered is shown in Table 3. The literature on this matter indicates that accessibility and other urban characteristics affect the location of different types of establishments. For example, a number of variables describe proximity to various landmarks, including distance to the nearest Metrosur Station, and distances to the traditional business district of the municipality, commuter train station, and interurban bus stop. Additional variables were considered in order to describe the potential of the market (i.e. population density: POPDEN) and the

Table 2

Economic sectors analyzed.

\begin{tabular}{llr}
\hline Sector & Description & Observations \\
\hline BC 1 & Manufacturing firms & 418 \\
BC 2 & Construction firms & 476 \\
BC 3 & Retail and related business activities & 1139 \\
BC 4 & Food service and hotel business activities & 444 \\
BC 5 & Transport, storage and communication firms & 305 \\
BC 6 & Finance, insurance, real estate, rental and other & 562 \\
& enterprise services & \\
BC 7 & Health and vet; social services; cultural and & 474 \\
BC 8 & recrational; sport activities & 117 \\
BC 9 & Vacant & 4219 \\
& Total & 8154 \\
\hline
\end{tabular}


Table 3

Explanatory variables used in the specification of the models.

\begin{tabular}{|c|c|c|}
\hline Variable & Units & Description \\
\hline SECTOR & & Dependent variable. 1 if that location is in use by the/business activity in 2007 \\
\hline MS_DISTNET & $\mathrm{km}$ & Street network distance from each possible location to the closest Metrosur station \\
\hline CBD_DISTNET & $\mathrm{km}$ & Street network distance from each possible location to Alcorcon downtown \\
\hline CER_DISTNET & $\mathrm{km}$ & Street network distance from each possible location to the closest commuter train station (Cercanias) \\
\hline INT_DISTNET & $\mathrm{km}$ & Street network distance from each possible location to the closest Interurban bus stop \\
\hline ROADEXIT_D & $\mathrm{km}$ & Street network distance from each possible location to the closest motorway exit \\
\hline ROAD_DEN & $10 \mathrm{~km} / \mathrm{km}^{2}$ & Street density around $100 \mathrm{~m}$ for each location \\
\hline POPDEN & $1000 / \mathrm{km}^{2}$ & Population density around $100 \mathrm{~m}$ for each location \\
\hline c & & Constant \\
\hline$r^{\mathrm{BC} 1}(1998: 100 \mathrm{~m})$ & Proportion & At each location, the vector of BC1 firms around $100 \mathrm{~m}$ in 1998 \\
\hline$r^{B C 2}(1998: 100 \mathrm{~m})$ & Proportion & At each location, the vector of $\mathrm{BC} 2$ firms around $100 \mathrm{~m}$ in 1998 \\
\hline$r^{B C 3}(1998: 100 \mathrm{~m})$ & Proportion & At each location, the vector of BC3 firms around $100 \mathrm{~m}$ in 1998 \\
\hline$r^{B C 4}(1998: 100 \mathrm{~m})$ & Proportion & At each location, the vector of BC4 firms around $100 \mathrm{~m}$ in 1998 \\
\hline$r^{B C 5}(1998: 100 \mathrm{~m})$ & Proportion & At each location, the vector of BC5 firms around $100 \mathrm{~m}$ in 1998 \\
\hline$r^{B C 6}(1998: 100 \mathrm{~m})$ & Proportion & At each location, the vector of BC6 firms around $100 \mathrm{~m}$ in 1998 \\
\hline$r^{B C 7}(1998: 100 \mathrm{~m})$ & Proportion & At each location, the vector of $\mathrm{BC} 7$ firms around $100 \mathrm{~m}$ in 1998 \\
\hline$r^{B C 8}(1998: 100 \mathrm{~m})$ & Proportion & At each location, the vector of BC 8 firms around $100 \mathrm{~m}$ in 1998 \\
\hline
\end{tabular}

built environment (i.e. road density: ROAD_DEN). Finally, spatial agglomeration of firms is measured by means of a location-specific occupancy ratio variable $\left(r_{i}^{k}\right)$, which the number of economic activities of a certain type $k$ that were located in the neighborhood of a specific location $i$ in 1998. This variable is used to assess the hypothesis that location patterns are influenced by proximity to certain types of activities.

All of the spatial variables described above are used to characterize the local environment of a portal. Occupancy ratio in particular was calculated using a spatial weights matrix (Bailey and Gatrell, 1995). The spatial weights matrix defines, for each location in the analysis, the neighbors within a specified radius. Sites within that radius are assigned a value of 1 or a value of zero otherwise. This binary matrix was combined with the occupation statistics of 1998. Sector-specific occupancy ratios were defined for each of the eight sectors in the analysis. This was done by dividing the number of establishments of type $i$ by the total number of sites (including vacant) in the same area. This gives a measure of geographical clustering of business that allows us to analyze whether the location of economic activities is influenced, in addition to proximity to transportation infrastructure, by agglomeration economies. A radius of $100 \mathrm{~m}$ was selected for the spatial weights matrix after extensive sensitivity analysis of model fit.

Some variables of interest were not available. In particular, land rent statistics do not exist. In a similar way, employment statistics could not be used since the datasets on this matter are very limited, especially in 1998. Moreover, the existent information about jobs is very broadly categorized, which greatly limits its usability.

\section{Methods and models}

Data processing was conducted using a Geographic Information System (GIS). GIS integrates the information to be managed under one system. It provides important tools for transportation research and planning, from pre-processing and processing of data, to fundamental spatial analysis operations such as the calculation of distances, areas, frequencies, and spatial relationships (Hsiao et al., 1997; Miller and Shaw, 2001) This research takes into account the distances from each location to the different facilities evaluated, such as the closest metro station through the street network, which increases the confidence in the analysis through the use of actual distances between points (Gutiérrez and García-Palomares, 2008; Mejia-Dorantes et al., 2011).

In terms of the analysis, we adopt a spatial statistical approach to the analysis of urban systems (Páez and Scott, 2004). We begin with a spatial description of the spatial pattern of firms. A useful descriptive statistic is obtained by means of kernel surfaces to investigate the density of a point pattern. While the descriptive statistic can provide evidence of clustering, it does not help to explain the factors that may cause the pattern. Therefore, we also apply a spatial modeling approach based on multinomial logit models to tease out the contribution of different factors that help explain the location decision of firms.

\subsection{Point pattern}

There are different statistical methods to analyze urban patterns. One of them is the point pattern analysis, which evaluates the distribution of events over an urban area. To analyze the firm location evolution over time and its clustering, the kernel estimation method for point pattern analysis can be used. Kernel surfaces are a powerful tool for the exploration of the spatial and temporal characteristics of clustering (Bailey and Gatrell, 1995; Cressie, 1991). This type of analysis has been implemented in the past in urban analysis by, among others, Cuthbert and Anderson (2002) and Maoh et al. (2010). It generates density surfaces that show where point features are concentrated, which in this case allows the identification of zones with high density of firms. The outcome is a continuous surface which represents the number of firms by business activity per square meter in the years 1998 (before the metro line was introduced) to 2007 (when the completed line was in full operation).

Kernel estimation is an extension of the moving window approach. It was originally developed to obtain a smooth estimate of a univariate or multivariate probability density from an observed sample of observations; in other words, a smooth histogram. Estimating the intensity of a spatial point pattern is very like estimating a bivariate probability density and bivariate kernel estimation can be easily adapted to give an estimate of intensity (Bailey and Gatrell, 1995).

If $s$ represents a general location in $R$ and $s_{1}, \ldots, s_{n}$ are the locations of the $n$ observed events then the intensity, $\lambda(s)$, at $s$ is estimated by:

$\hat{\lambda}(s)_{\tau}=\frac{1}{\delta_{\tau}} \sum_{i=1}^{n} \frac{1}{\tau^{2}} k\left(\frac{s-s_{i}}{\tau}\right)$

Here $k(\bullet)$ is a suitably chosen bivariate probability density function, known as the kernel, which is symmetric about the origin. The parameter $\tau>0$ is known as the bandwidth and determines the 
amount of smoothing, essentially it is the radius of a disk centered on $s$ within which points $s_{i}$ will contribute significantly to $\lambda_{\tau}(s)$. Edge corrections are also used.

There are different possible functional forms of the kernel estimate. ArcGis uses the Quadratic normalized function, where distances have been divided by the kernel bandwidth (De Smith et al., 2007). As a smoothing, exploratory technique, the bandwidth for the kernel is selected by visual inspection of the results in order to discover potential patterns. Further information regarding the theory about intensity functions can be found at Bailey and Gatrell (1995), Cressie (1991), and De Smith et al. (2007).

\subsection{Model}

The proposed model is based on the population of sites (portals) available for commercial activities, and the probability that a specific site will be occupied by a specific form of activity. The variables used in the analysis are presented in Table 4 . The analysis is conducted using the multinomial logit model (MNL).

The multinomial logit model (MNL) is commonly used in transportation studies. It is an extension of the simple logit model for dichotomous variables. The form of the logit model prevalent in transportation applications is based on McFadden's random utility approach to model discrete choices (the so-called conditional logit). Previous studies have, in analogy to random utility, framed firm locational processes as the outcome of a profit maximization approach. Firms are the unit of analysis, and the locations are the outcome of their choices. In the present case we apply instead a probabilistic model that sees the portal as the unit of analysis, and its state as the outcome. Each portal can, at a given time, be in one and only one of a finite set of states: vacant or occupied by an establishment of type $j$.

To some extent, the selection of a probabilistic model is dictated by our data availability situation. While profit maximization is compatible with economic theory, it requires information about the firms, attributes which are not known in our case. Furthermore, it is quite possible that one firm could have in fact a number of establishments, i.e., that it operates out of various locations again, a piece of information that was not available. The technical differences between the choice-based and probabilistic approaches are rather minimal, but important from a conceptual and practical perspective. As an approach to model locational firm patterns, our probabilistic approach loses some economic theoretical appeal. On the other hand, it helps us circumvent some serious data and modeling issues, including the treatment of single firms owning multiple establishments.

Herein, two models were tested. First, a MNL was estimated using all variables with the exception of the occupancy ratios that account for the information of the spatial relationship with business activities in 1998 (Model 0). In the second model (Model 1), occupancy ratios were introduced. This expanded model provided a better fit. Model 0 is used for the Likelihood Ratio test (LR test), which is the statistical test for comparing two different models when one of them is a special case of the other. Due to space constraints, only Model 1 is presented in this paper. In the model, one of the outcome classes is arbitrarily set as the base outcome. For ease of interpretation, in this study we select vacant as the reference category.

The multinomial logit probability for outcome $j$ can be presented as:

$$
P_{j}=\frac{e^{\beta_{j}^{\prime} x}}{1+\sum_{j=1}^{m-1} e^{\beta_{j}^{\prime} x}}
$$

The spatial version of the model incorporates a spatial weights matrix as described above. Now the probability of a portal being in state $j$ depends on a set of covariates $x$ and also the presence/absence of other businesses in the neighborhood. The weights in matrix $\mathbf{W}$ are defined as follows:

$$
w_{i j}= \begin{cases}1 & \text { if } d_{i j} \leqslant d^{*} \text { for } i \neq j \\ 0 & \text { otherwise }\end{cases}
$$

where $d_{i j}$ is the distance between locations $i$ and $j$, and $d^{*}$ is a critical cut-off distance ( $100 \mathrm{~m}$ in our case).

Further, we define vectors of occupancy as a set of dummy variables that indicate for each available location its occupancy status:

$$
O_{i}^{k}= \begin{cases}1 & \text { if portal } i \text { was of type } \mathrm{k} \text { in } 1998 \\ 0 & \text { otherwise }\end{cases}
$$

Table 4

\begin{tabular}{|c|c|c|c|c|c|c|c|c|c|c|c|}
\hline Var & Units & Min & $\operatorname{Max}$ & $\mathrm{BC} 1$ & $\mathrm{BC} 2$ & $\mathrm{BC} 3$ & $\mathrm{BC} 4$ & $\mathrm{BC} 5$ & $\mathrm{BC} 6$ & $\mathrm{BC7}$ & BC 8 \\
\hline \multicolumn{12}{|c|}{ Model 1. (reference is B9: vacant) } \\
\hline MS_DISTNET & $\mathrm{km}$ & 0 & 6.3657 & -0.5384 & -0.5125 & -0.6054 & -0.6948 & -0.5498 & -0.4948 & -0.4754 & -0.7923 \\
\hline CBD_DISTNET & $\mathrm{km}$ & 0.017 & 6.6227 & -0.9165 & -0.1299 & -0.2837 & -0.0989 & 0.0218 & -0.0565 & 0.0621 & -0.2053 \\
\hline CER_DISTNET & $\mathrm{km}$ & 0.0771 & 6.3354 & 1.5329 & 0.6732 & 0.9177 & 0.4812 & 0.3591 & 0.3776 & 0.2057 & 0.3825 \\
\hline INT_DISTNET & $\mathrm{km}$ & 0 & 2.4497 & 0.7399 & -0.8090 & 0.2047 & -0.9699 & -0.8615 & -0.0773 & -1.1065 & -1.5035 \\
\hline ROADEXIT D & $\mathrm{km}$ & 0.07 & 2.68 & -0.2909 & 0.1037 & -0.3234 & 0.0442 & 0.5016 & -0.1147 & 0.0350 & 0.2448 \\
\hline ROAD DEN $(100 \mathrm{~m})$ & $10 \mathrm{~km} / \mathrm{km}^{2}$ & 0.31 & 10.9 & -0.1264 & -0.0962 & -0.1438 & -0.2395 & -0.2543 & -0.1411 & -0.1935 & -0.2896 \\
\hline POP DEN $(100 \mathrm{~m})$ & $1000 / \mathrm{km}^{2}$ & 0 & 15.28 & 0.0072 & 0.0920 & 0.0884 & 0.1014 & 0.1130 & 0.0662 & 0.1122 & 0.0885 \\
\hline$r^{\mathrm{BC} 1}$ & Proportion & 0 & 0.6667 & 3.9774 & 1.1914 & 1.3198 & 0.2446 & 0.5996 & 1.4816 & 1.4426 & -1.3367 \\
\hline$r^{\mathrm{BC2}}$ & Proportion & 0 & 1 & 0.1271 & 1.2940 & -2.2504 & -1.0452 & -1.2131 & -0.5555 & -0.6822 & -5.1484 \\
\hline$r^{\mathrm{BC} 3}$ & Proportion & 0 & 1 & -0.9302 & -1.3777 & 0.5328 & -0.8203 & -1.0411 & -1.3306 & -1.5722 & -1.4046 \\
\hline$r^{B C 4}$ & Proportion & 0 & 1 & 2.9027 & 3.0523 & 2.9747 & 6.5152 & 3.2528 & 1.4986 & 1.2727 & 1.6257 \\
\hline$r^{\mathrm{BC5}}$ & Proportion & 0 & 0.5 & -3.4585 & -2.1089 & -3.1176 & -6.2806 & 0.3428 & -1.4351 & -2.3020 & -2.5277 \\
\hline$r^{B C 6}$ & Proportion & 0 & 0.5 & 0.8652 & 0.8466 & 2.1393 & 1.8591 & 2.8250 & 7.3588 & 3.6705 & 4.4106 \\
\hline$r^{B C 7}$ & Proportion & 0 & 1 & 4.4268 & 5.3570 & 4.1832 & 5.1395 & 3.8088 & 4.2552 & 8.1500 & 2.4487 \\
\hline$r^{\mathrm{BC8}}$ & Proportion & 0 & 0.5 & 2.4243 & -0.2755 & 0.6960 & 1.6662 & -0.9578 & 1.9388 & 3.7233 & 9.6891 \\
\hline Const & $\mathrm{km}$ & 1 & 1 & -2.6428 & -2.5146 & -1.5107 & -1.8525 & -2.7011 & -1.9175 & -1.8388 & -2.1901 \\
\hline
\end{tabular}

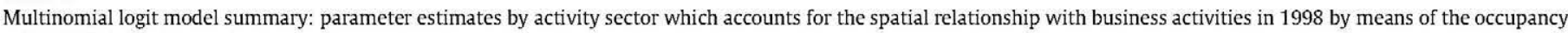
ratios. BC9 is the base outcome.

Observations $(n)=8154$.

Number of parameters in Model $0=7$; $\log$ likelihood model $0=-12363.65$.

Number of parameters in Model $1=15$; $\log$ likelihood model $1=-12105.82$.

LR test (vs Model 0 ) =515.68; " not significant at $5 \%$. 
The occupancy ratio at location $i$ for activity class $k$ gives a measure of agglomeration in the preceding time period. This ratio is calculated based on the spatial weights matrix and occupancy as follows:

$r_{i}^{k}=\frac{\sum_{j} w_{i j} O_{j}^{k}}{\sum_{j} w_{i j}}$

The value of $r_{i}^{k}$ is the number of available sites that were occupied by activities of type $k$ in 1998, divided by the total number of sites available for occupancy. The multinomial logit model with this spatial component becomes:

$P_{j}=\frac{e^{\beta_{j}^{\prime} x_{i}+\sum_{k} r_{i}^{r^{k}}}}{1+\sum_{j=1}^{m-1} e^{\beta_{j}^{\prime} x_{i}+\sum_{k} r_{i}^{k}}}$
The model in Eq. (6) is the multinomial version of the spatial logit model introduced by Dubin (1995) however using a binary weights matrix instead of a negative exponential distance decay. Similar models were used by Páez and Suzuki (2001) in their examination of land use change, and Páez and Scott (2007) with reference to social networks.

\section{Results}

The kernel surfaces show a different spatial variation pattern, depending on the type of activity at each location. Kernel estimation smoothes the data, therefore, white zones do not always imply a lack of economic activity within that area. It may only be very low relative to other areas where the value is higher. The maps

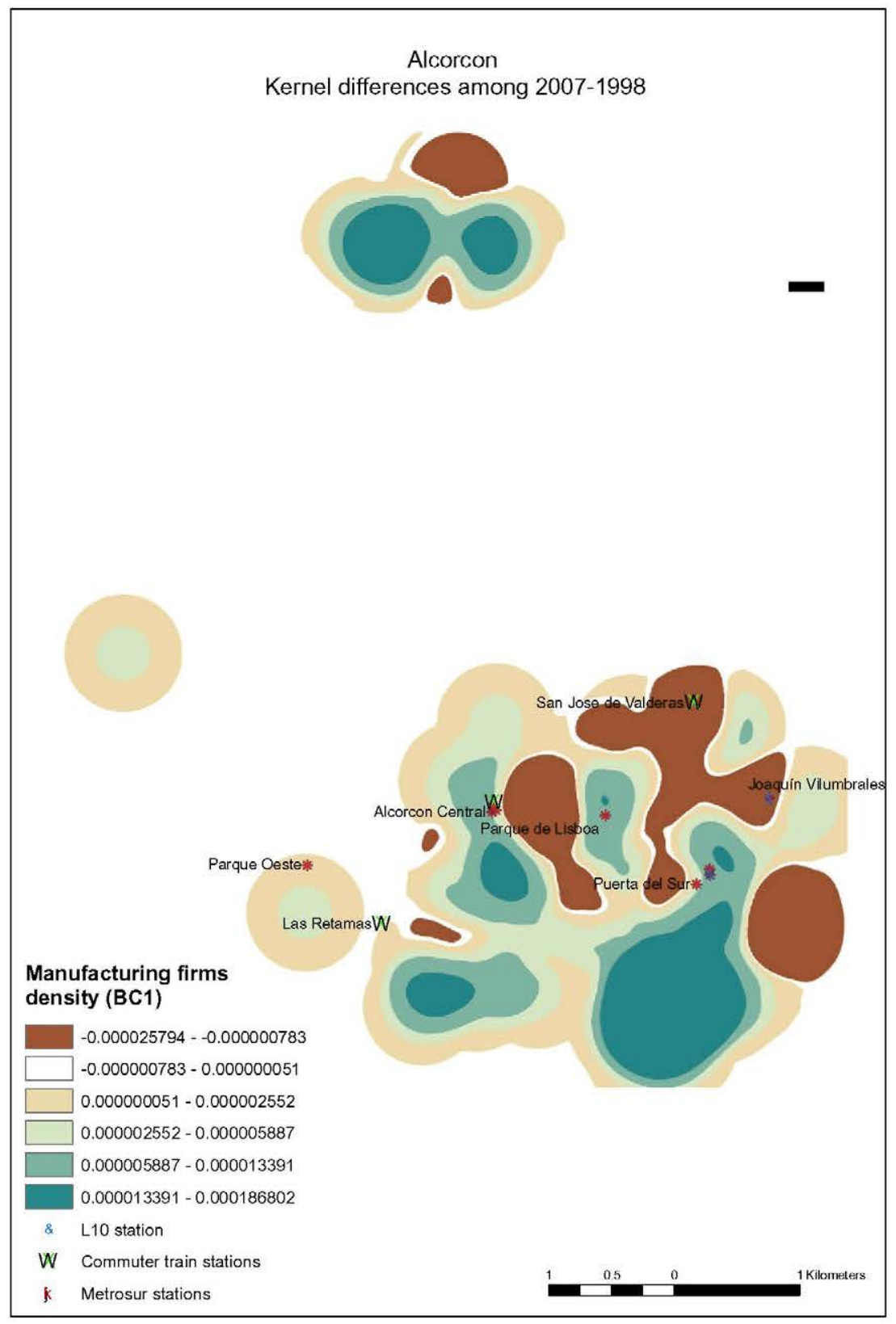

Fig. 5. Kernel density maps for different types of economic activities. They show the difference in economic activities between 2007 and 1998 . 


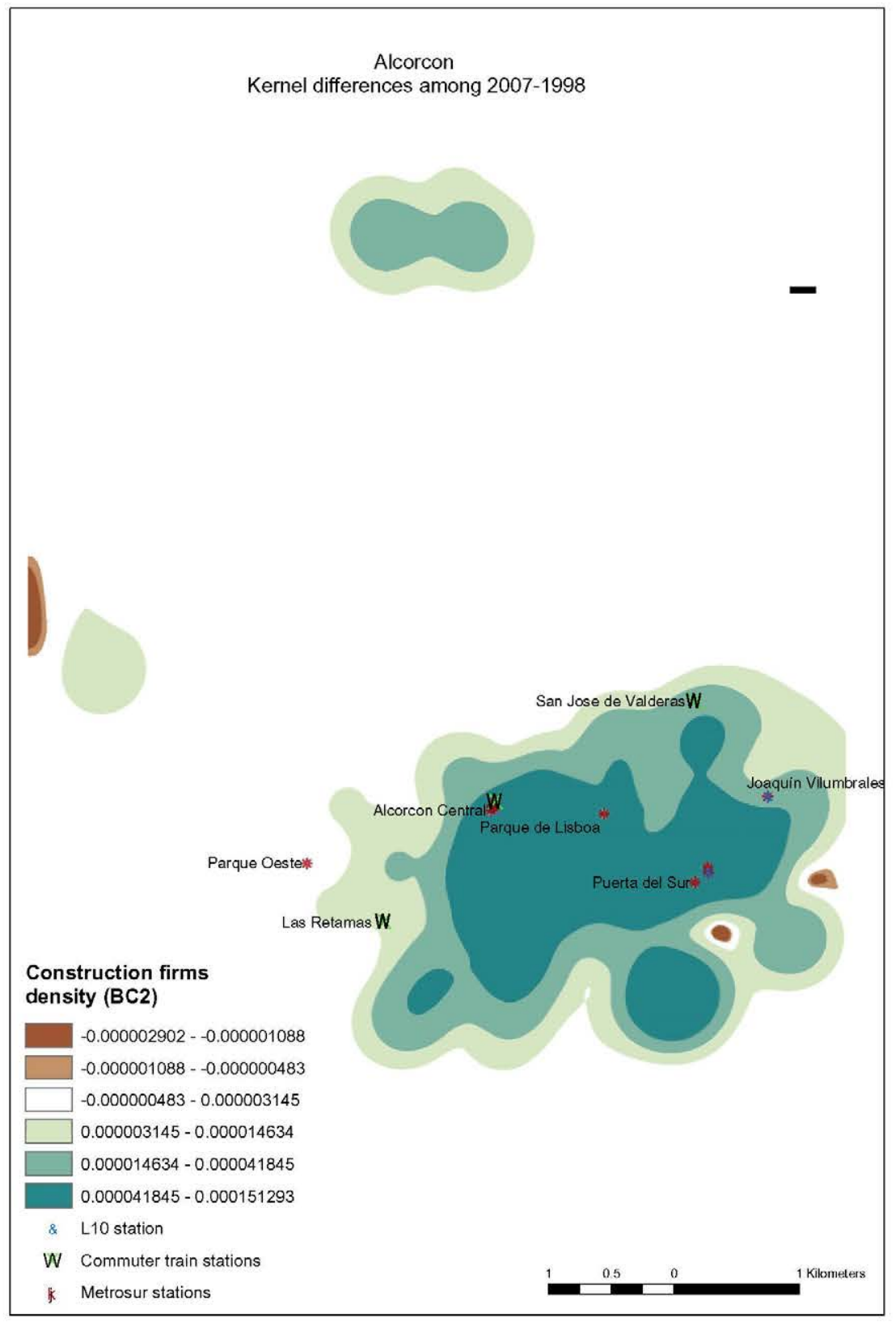

Fig. 6. Kernel density maps for different types of economic activities. They show the difference in economic activities between 2007 and 1998 .

(Figs. 5-11) provide relevant information regarding how each type of activity locates in space over time and how they cluster: They indicate the presence of clustering patterns while showing an increase in economic activities over time. Some of the economic activities have higher density changes than others. It is also possible to appreciate that the north of the Municipality did not display an important increase of economic activities. It is worth noting that densities tend to surround metro stations; that Sector B3 (retail and similar) presents the highest density pattern and that the location of economic activities diminishes near the commuter train station "Las Retamas" and the metro station "Parque del Oeste". Both these zones have low density development with wide streets, which may limit pedestrian mobility.

Interestingly, the pattern by manufacturing firms has not particularly increased its density in ten years, as can be seen in
Fig. 5 (BC1). This is the case of resource-oriented firms. It seems that the geographic location of Alcorcon and its proximity to Madrid City through different means of transport increases other kind of economic sectors, mainly market-oriented firms (Figs. 6-11, $\mathrm{BC} 2-\mathrm{BC} 7$ ).

The construction gives signs of an increased activity pattern through the territory. It is possible to appreciate a sprawling pattern, away from the local CBD. If we take into account that Alcorcon increased its population over the years, firms related to the construction sector were necessary for the housing needs.

Retail activities (BC3) tend to cover the surroundings of transport stations. This sector increased its activities in newer areas while in central Alcorcon areas it seems to have decreased. Different reasons might explain this trend: The lack of urban land availability due to a very dense street pattern, a mixed land use, and old 


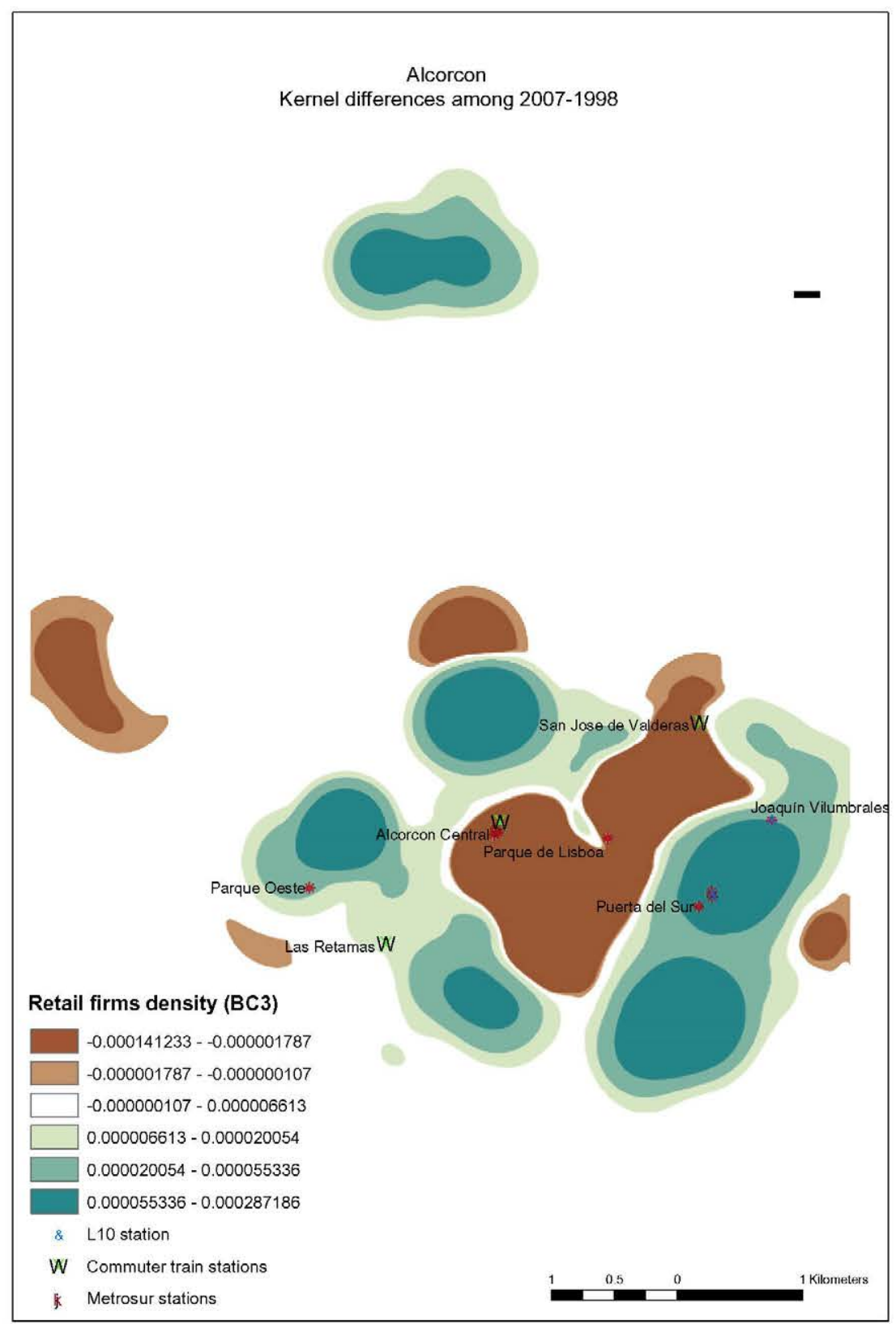

Fig. 7. Kernel density maps for different types of economic activities. They show the difference in economic activities between 2007 and 1998 .

urban development areas may limit the expansion of retail stores which may have to move to other zones with larger land availability and even with lower land prices.

The main changes in density patterns appear to have happened outside of the CBD. All sectors expand following the same sprawling pattern. The former impressions brought about by the descriptive spatial analysis are borne by the multivariate models. The parameter estimates of the multinomial logit model (Table 4), provide further insights into the location patterns of various sectors.

Model 1 shows that Metrosur is relevant for every sector of economic activity at a very high confidence level. Recalling that the reference outcome is "vacant", the models indicate that the probability of a portal being occupied decreases with increasing distance from the nearest Metrosur station. According to Model 1 , the effect is relevant in every case although there are slight differences depending on the type of economic activity. Model also shows that although the effect of agglomeration economies is al- ways positive, in the case of Alcorcon it is not always significant, as it can be noted on $\mathrm{BC} 2$ (Construction); $\mathrm{BC} 3$ (Retail) and $\mathrm{BC5}$ (Transport, Storage and Communications). It implies that especially in the case of those economic activities, they have been drawn to a site with good accessibility, which is in general related to Metrosur, as it is explained in the following paragraphs.

It is interesting to discuss the commuter train effect, Cercanias, since it seems not to be significant for some economic activities. Kernel surfaces showed that Las Retamas station has not attracted firms during these 10 years. It is known that many times environmental quality might impact the location of economic activities close to the stations: A subway impacts positively whereas a ground line, like Cercanias, provokes some negative externalities related to noise, barrier effects and a deteriorated urban landscape. Finally, in the case of Alcorcon, Metrosur provides the same service than Cercanias (through Puerta del Sur station which is the transfer to line 10 that goes to Madrid City) and much better, since it is a 


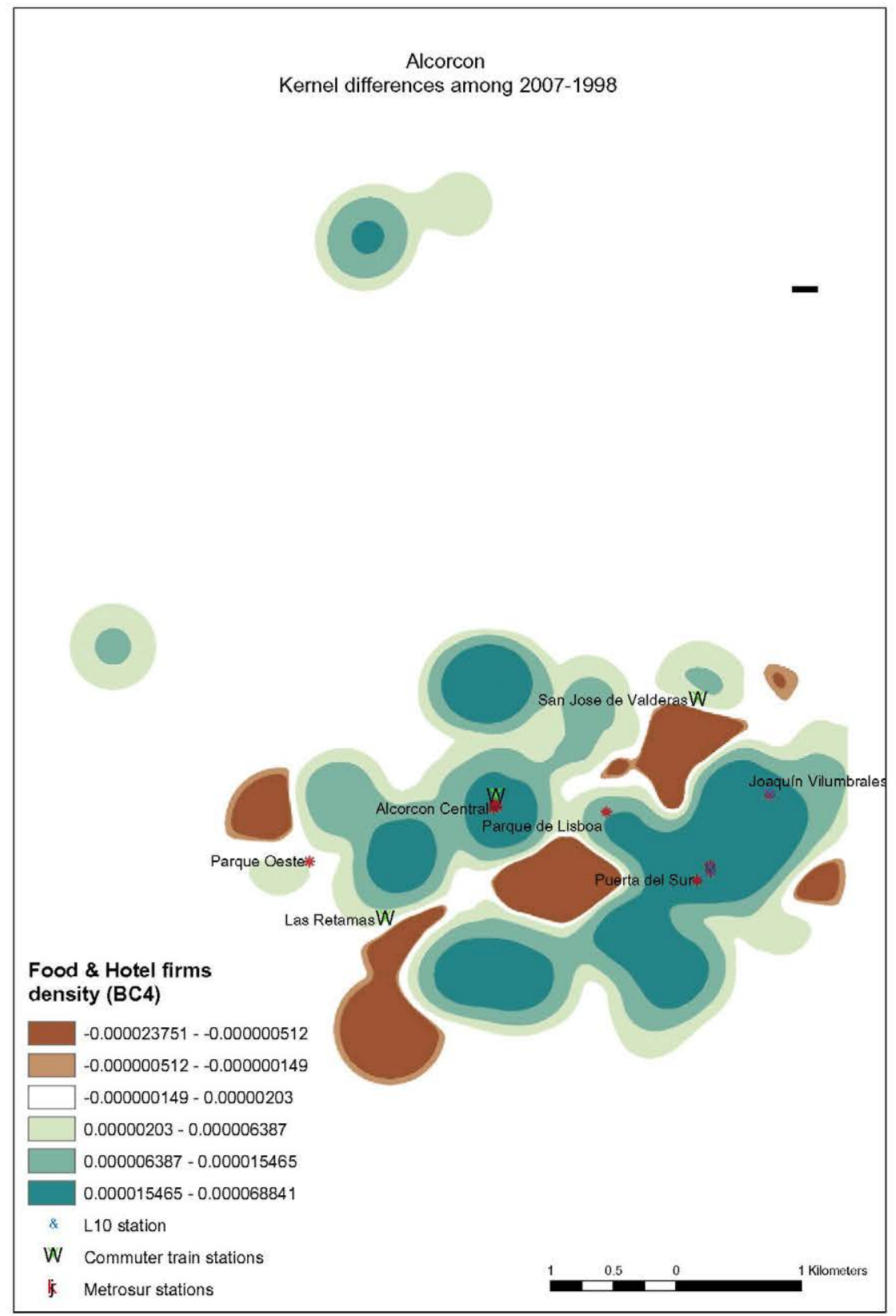

Fig. 8. Kernel density maps for different types of economic activities. They show the difference in economic activities between 2007 and 1998.

newer transport infrastructure, and it connects to the surrounding municipalities, whereas Cercanias only connects to the Municipality below, Mostoles, and to Madrid City.

Population density plays an important role in the location of economic activities. Areas with low population density such as semi-detached or detached houses limit the location of businesses. It implies that, in order to have the maximum profitability of the public transport infrastructure, TOD strategies should accompany the location of stations. These results are also in the line with Maoh et al. (2010), which affirm that there is a strong dependency among residential and commercial land uses.

In the case of road density, both models offer similar results: A higher road density decreases the probability of location of any economic activity. One of the explanations might be that higher density patterns are located in downtown and as kernel maps show, the trend is that economic activities are sprawl, which implies more land availability. On the other hand, distance to the closest motorway exits seems not to be an important factor when locating any type of business activity within Alcorcon. Hence, this would mean that neither of both road accessibility indicators is important when locating an economic activity, since the whole municipality benefits from good motorway accessibility: It should be borne in mind that the Madrid metropolitan area has one of the highest rates of kilometers of motorways per habitant in Europe (Fundación de la energía de la Comunidad de Madrid, 2010).

Regarding the variable $C B D$, model 1 shows that in most of the cases, distance to Alcorcon downtown is not relevant. The parameter suggests that Alcorcon does not follow a monocentric pattern. This parameter is consistent with the Kernel surfaces.

In the case of interurban buses, the model suggests that being closer to a bus stop in some cases implies a greater opportunity for a business activity, however in other cases it is not significant.

The $r^{\mathrm{BC}}$ variables for all sectors shed some light on the importance of economic agglomeration. Being in 2007 in a location where 


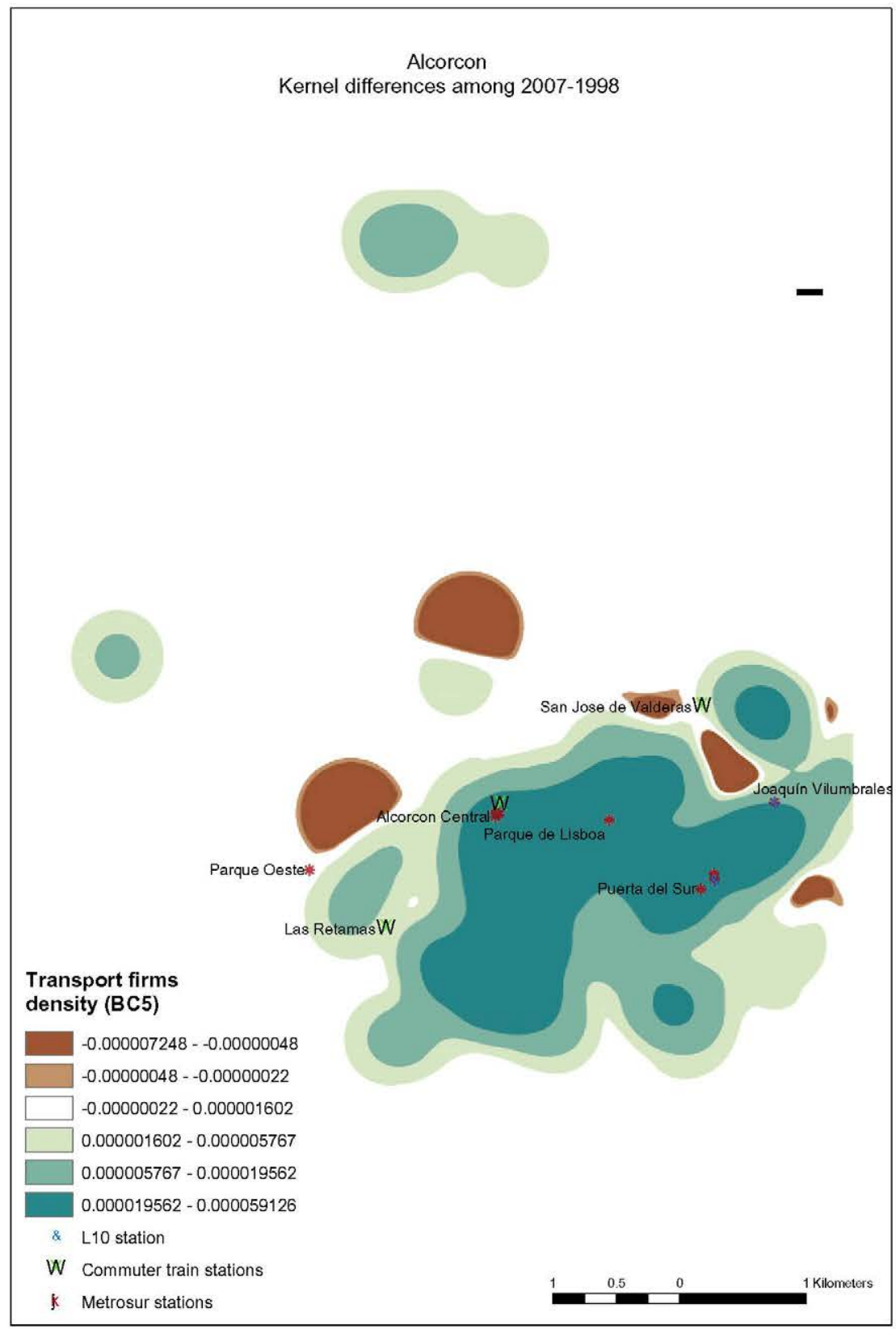

Fig. 9. Kernel density maps for different types of economic activities. They show the difference in economic activities between 2007 and 1998 .

there was already the same group business activities in 1998 (principal diagonal) increases the probability of locating a firm related to the same sector. This statement holds except for $\mathrm{BC} 2, \mathrm{BC} 3$ and $\mathrm{BC} 5$.

Finally, the model sheds some light on the location dynamics of economic activities within this region. There seems to be some advantages or disadvantages on the location of different types of economic activities as a result of the development of local markets or the reaction to competition. For instance, in 1998 an area with retail activities $\left(r^{\mathrm{BC} 3}\right)$ decreases the probability of location of other types of economic activities, but it increases the location of the same type of activity in 2007 . This statement might be related to the higher land values, to the lack of land availability or to a rejection to competition. On the other hand, in 1998 an area with neighboring financial activities $\left(r^{\mathrm{BC} 6}\right)$ increases the probability of locating any type of economic activities in 2007, which might be related to economies of scale.

\section{Discussion and conclusions}

The objective of this paper has been to analyze economic activity spatial patterns using spatial analysis techniques and models, along with a detailed data base. Herein, we examined the locational pattern and relevant factors for different industry sectors within the territory of Alcorcon. In particular, the analysis has been of how this location pattern changed following the introduction of a new major rail transit project. The results indicate the presence of spatial clusters. They also show an increase in economic activities over time, with retail activities displaying the highest pattern of concentration. This is consistent with their market orientation. It seems that market-oriented firms have displaced manufacturing firms within the territory.

The evidence is supported by means of a multinomial logistic regression, where we investigate how businesses by group sector (manufacturing, construction, retail services, food services, trans- 


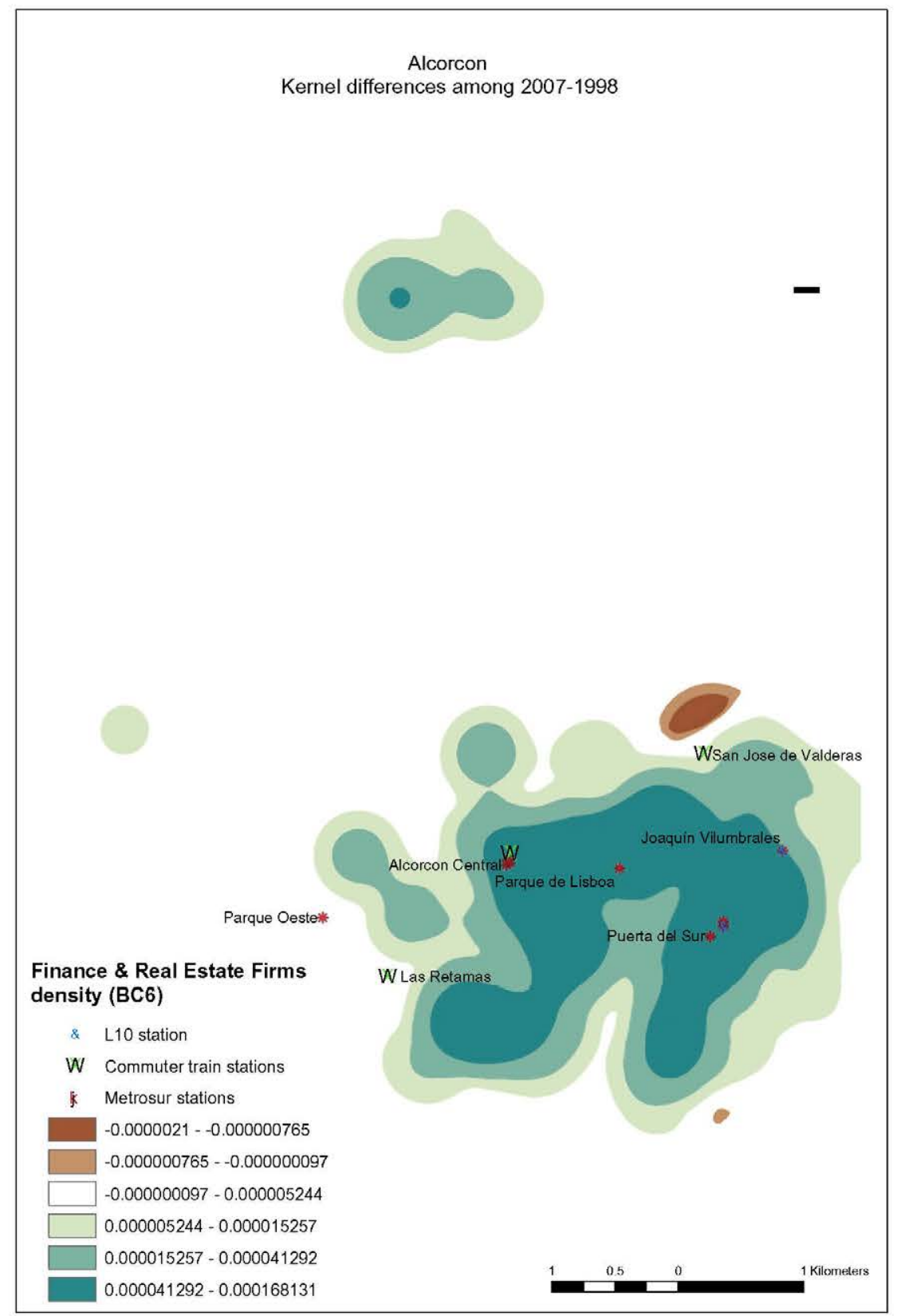

Fig. 10. Kernel density maps for different types of economic activities. They show the difference in economic activities between 2007 and 1998.

port and finance and real estate) are related to urban characteristics, such as distance to different public transport infrastructure; population and street network densities; local CBD and a ratio of business occupation around each location point in 1998. Our estimates show that firms benefit from neighborhood characteristics. We conclude that the changes in accessibility related to Metrosur affected the locational pattern and generated a tendency to locate near Metro stations. However, and this is a key point supported by our use of spatial modeling approaches, the pattern is also a consequence of agglomeration economies and other neighborhood characteristics such as the location around places with higher population, which may be seen as zones with more potential clients or workers. It is important to note that the types of firms where agglomeration with the same type of activities were not significant are the ones related to construction, transport and retail which might be a consequence, in addition to the nature of these activities, of land availability constraints and other macro-level factors, such as the general geographic situation of the municipality within the region.

In summary, this paper contributes to the literature on the assessment of economic impacts of public transport infrastructure and on industrial locational patterns. The use of spatial models provides appropriate tools to approach the question of to what extent new infrastructure and agglomeration have an impact on the location of economic activities. More substantively, we found that Alcorcon does not follow the theoretic monocentric urban form since distance to the core is not significant and kernel surfaces show a sprawl pattern around transport stations, which means that public transport stations, especially by means of Metrosur, have helped to strengthen the economic linkages to other municipalities and to Madrid City. This information is useful to developers, urban planners and practitioners interested in more efficient urban and transport planning. As further research, it will be interesting to apply a similar approach to analyze the situation in other municipalities served by 


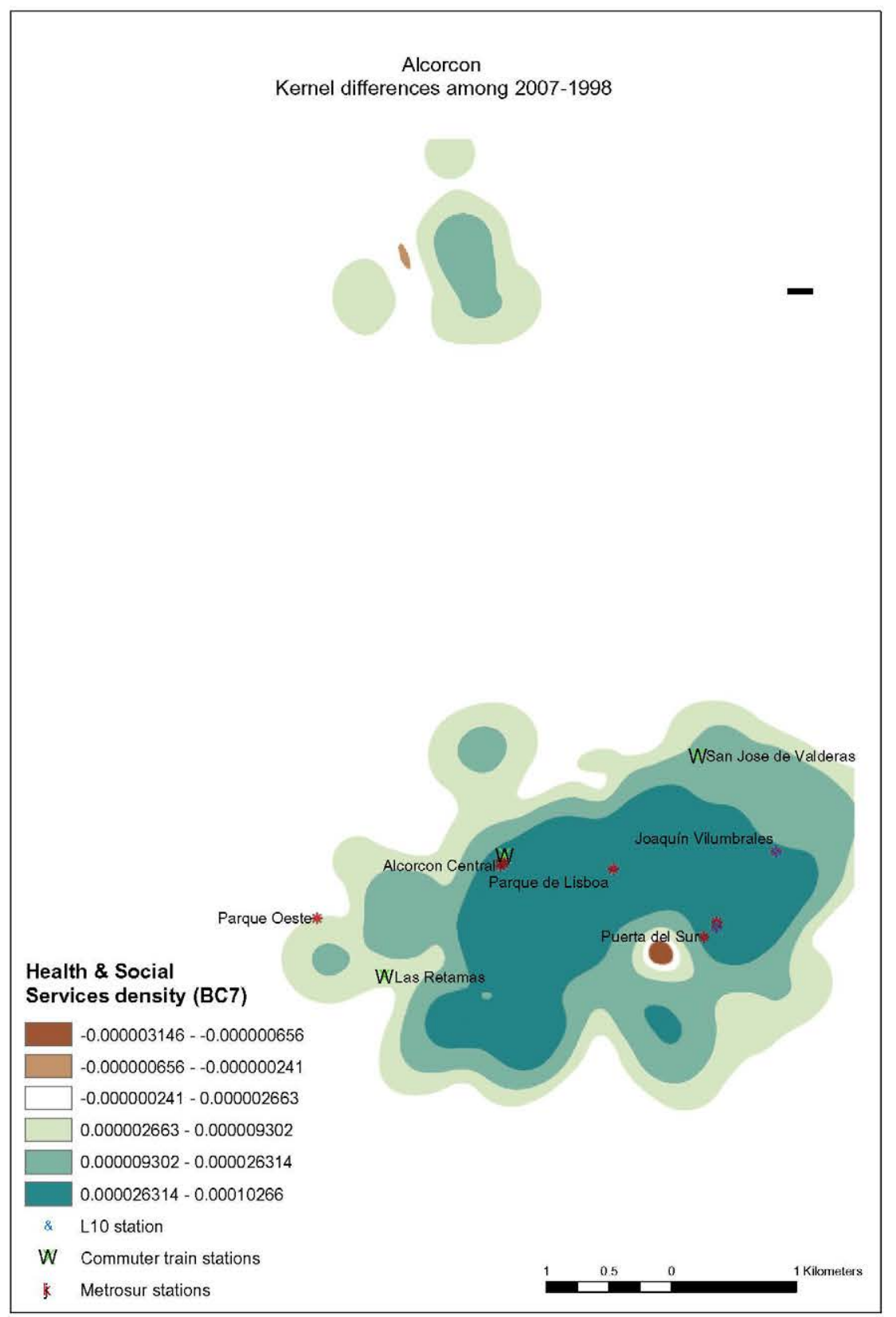

Fig. 11. Kernel density maps for different types of economic activities. They show the difference in economic activities between 2007 and 1998.

Metrosur. More generally, the approach used here should be applicable to other cities, as long as similar databases can be obtained. Finally, this paper leaves many doors opened for future research, such as an analysis among parameters of the five municipalities connected by Metrosur, which could be of great interest.

The authors would like to thank the Bureau of Statistics of the Madrid Region for the information shared with us to carry out this research. Financial support from the Ministry of Science and Innovation of Spain (TRA2006-07008) is gratefully acknowledged.

Bailey, T.C., Gatrell, A.C., 1995. Interactive Spatial Data Analysis. Longman Harlow, Essex, UK.
Banister, D., Berechman, J., 2000. Transport Investment and Economic Development. Routledge.

Banister, D., Berechman, Y., 2001. Transport investment and the promotion of economic growth. Journal of Transport Geography 9 (3), 209-218.

Baumont, C., Ertur, C., Le Gallo, J., 2004. Spatial analysis of employment and population density: the case of the agglomeration of Dijon 1999. Geographical Analysis 36 (2), 146-177.

Beckmann, M.J., 1999. Lectures on Location Theory. Springer, Germany.

Boarnet, M.G., 2006. Conducting Impact Evaluations in Urban Transport. Doing Impact Evaluation Series 5. The World Bank.

Bureau of Statistics of the Madrid Region, 2011. Database: Municipalities' Files, 2011 (10/01).

Cervero, R., Aschauer, D.A., 1998. Economic Impact Analysis of Transit Investments: Guidebook for Practitioners. Cambridge Systematics, National Research Council (US), Washington, DC.

Cohen, J.P., Paul, C.J.M., 2005. Agglomeration economies and industry location decisions: the impacts of spatial and industrial spillovers. Regional Science and Urban Economics 35 (3), 215-237.

Cressie, N., 1991. Statistics for Spatial Data. John Wiley and Sons, Inc., USA.

CRTM - Consorcio Regional de Transportes de Madrid, 2006. Encuesta domiciliaria de movilidad en día laborable de 2004 en la Comunidad de Madrid. Resumen de Resultados. 
Cuthbert, A.L., Anderson, W.P., 2002. Using spatial statistics to examine the pattern of Urban Land development in Halifax-Dartmouth. The Professional Geographer $54(4), 521-532$

De Smith, M.J., Goodchild, M.F., Longle, P., 2007. Geospatial Analysis: A Comprehensive Guide to Principles. Techniques and Software Tools. Matador, Leicester.

Dubin, R., 1995. Estimating logit models with spatial dependence. In: Anselin, L. Florax, R. (Eds.), New Directions in Spatial Econometrics. Springer-Verlag, Heidelberg, pp. 229-242.

Feser, E.J., Sweeney, S.H., 2000. A test for the coincident economic and spatial clustering of business enterprises. Journal of Geographical Systems 2 (4), 349373

Fujita, M., 1989. Urban Economic Theory: Land Use and City Size. Cambridge University Press, UK.

Fundación de la energía de la Comunidad de Madrid, 2010. Movilidad urbana sostenible: Un reto energético y ambiental.

Gutiérrez, J., Garcia-Palomares, J.C., 2008. Distance-measure impacts on the calculation of transport service areas using GIS. Environment and Planning B: Planning and Design 35 (3), 480-503.

Hoover, E.M., Giarratani, F., 1971. An Introduction to Regional Economics. McGrawHill, New York.

Hsiao, S., Lu, J., Sterling, J., Weatherford, M., 1997. Use of geographic information system for analysis of transit pedestrian access. Transportation Research Record: Journal of the Transportation Research Board 1604, 50-59.

Johansson, B., Quigley, J.M., 2003. Agglomeration and networks in spatial economies. Papers in Regional Science $83(1), 165-176$.

Jordá, P., 2009. Time use constraints in multimodal trips making. In: Proceedings Young Researches Seminar.

Le Gallo, J., Chasco, C., 2008. Spatial analysis of urban growth in Spain, 1900-2001. Empirical Economics 34 (1), 59-80.

Manzato, G., Arentze, T., Timmermans, H., Ettema, D., 2011. Exploring location influences on firm survival rates using parametric duration models. In: Transportation Research Board 90th Annual Meeting.

Maoh, H.F., 2005. Modeling Firm Demography in Urban Areas with an Application to Hamilton, Ontario: Towards an Agent-Based Microsimulation Model. ETD Collection for McMaster University.

Maoh, H., 2007. Business establishment mobility behavior in urban areas: a microanalytical model for the City of Hamilton in Ontario, Canada. Journal of Geographical Systems 9 (3), 229-252.

Maoh, H., Kanaroglou, P., 2007. Geographic clustering of firms and urban form: a multivariate analysis. Journal of Geographical Systems $9(1), 29-52$.
Maoh, H., Kanaroglou, P., 2009. Location of business establishments: a microanalytical model for the City of Hamilton in Ontario, Canada. Transportation Research Record: Journal of the Transportation Research Board 2133, 33-45.

Maoh, H.F., Koronios, M., Kanaroglou, P., 2010. Exploring the land development process and its impact on urban form in Hamilton, Ontario. Canadian Geographer/Le Géographe Canadien 54 (1), 68-86.

Mas, M., Maudos, J., 2004. Infraestructuras y Crecimiento Regional En España Diez Años Después. In: Villaverde Castro, J. (Ed.), Competitividad Regional En La Unión Europea Ampliada, first ed. Instituto de Estudios Fiscales, p. 143.

Mejia-Dorantes, L., Vassallo, J., 2010. Does A New Metro Line Promote Business Activities Close to Its Stations? Case study of Metrosur in Madrid. TRANSyT Working Papers: 2010-01-EN (February 25, 2010)

Mejia-Dorantes, L., Paez, A., Vassallo, J., 2011. Analyzing house prices to assess economic impacts of new public transport infrastructure: Madrid metro line 12. Transportation Research Record: Journal of the Transportation Research Board.

Melis, M., Arnaiz, M., Trabada, J., Díaz, J. M., Olivé, R., González, A., Alonso, J.P., de Matías, I., Lera, M., Diez, J.C., Herrera, M., Juncá, J.A., 2003. Metrosur, first ed. Comunidad Autonoma de Madrid, Madrid. ISBN: 9788445124741.

Miller, H.J., Shaw, S.L., 2001. Geographic Information Systems for Transportation: Principles and Applications. Oxford University Press, USA

Páez, A., Scott, D.M., 2004. Spatial statistics for urban analysis: a review of techniques with examples. GeoJournal 61, 53-67.

Páez, A., Scott, D.M., 2007. Social influence on travel behavior: a simulation example of the decision to telecommute. Environment and Planning A 39 (3), 647-665.

Páez, A., Suzuki, J., 2001. Transportation impacts on land use change: an assessment considering neighborhood effects. Journal of the Eastern Asia Society for Transportation Studies 4 (6), 47-59.

Ryan, J., Maoh, H., Kanaroglou, P., 2009. Population synthesis: comparing the major techniques using a small, complete population of firms. Geographical Analysis 41 (2), 181-203.

Schwanen, T., Dijst, M., Dieleman, F.M., 2004. Policies for urban form and their impact on travel: the Netherlands experience. Urban Studies 41 (3), 579-603.

Small, K.A., 1982. Geographically Differentiated Taxes and the Location of Firms. Princeton Urban and Regional Research Center, Princeton, New Jersey.

Spain National Statistics Bureau, 2010. Madrid Urban Transportation, 2011 (02/02/ 2011).

TARYET \& IMOP, 2005. Aspectos socioeconómicos y de movilidad. Resumen ejecutivo de la encuesta domiciliaria de movilidad de 2004 en la Comunidad de Madrid.

Yrigoyen, C.C., Garcia, A.M.L., 2009. In: Paez, A., Gallo, J., Buliung, R., Dall'erba, S. (Eds.), Evolution of the Influence of Geography on the Location of Production in Spain. Springer, pp. $407-440$. 